\title{
ESTUDIO TECNO-TIPOLÓGICO DE CUATRO CONJUNTOS LÍTICOS PALEOLÍTICOS DE SUPERFICIE EN VILALLONGA (VALENCIA) Y LA VALL DE GALLINERA (ALICANTE)
}

\author{
TECHNO-TYPOLOGICAL STUDY OF FOUR SURFACE PALEOLITHIC LITHIC GROUPS IN \\ VILALLONGA (VALENCIA) AND VALL DE GALLINERA (ALICANTE)
}

\author{
MIGUEL ÁNGEL BEL MARTÍNEZ \\ Universitat de València \\ ALEIX EIXEA VILANOVA \\ Universitat de València
}

\section{INTRODUCCIÓN}

En estas líneas se presenta el estudio tecno-tipológico de los materiales líticos recogidos al sur del término de Vilallonga (Valencia) y norte del de la Vall de Gallinera (Alicante). Se trata de conjuntos que proceden de lugares distintos: Les Majones, La Llacuna, Pla de Palau y un cuarto lote sin adscripción geográfica clara guardado en una bolsa sin etiquetar junto a los materiales de Les Majones y La Llacuna, estudiado este último como un cuarto conjunto diferenciado del resto y denominado en el texto como Majones-Llacuna. No se trata de materiales recogidos en el marco de prospecciones o estudios sistemáticos de la zona, sino que fueron recuperados a lo largo de varias visitas al lugar -de las que se desconocen los detalles- por Manuel Sánchez, circunstancia que ha sido tenida en cuenta en la investigación desarrollada. Conviene destacar que la zona de La Llacuna ya contaba con un estudio etnográfico y arqueológico previo, en el que se presentaron algunos conjuntos líticos adscritos a finales del Paleolítico e inicios del Epipaleolítico (Beavitt et alii, 1995). Los conjuntos analizados en el presente trabajo se suman a otro ya publicado en la Vall de Gallinera, Els Bancals de Pere Jordi (Eixea y Villaverde, 2012), de características similares. Con este estudio se pretende definir los principales rasgos de dichos conjuntos y valorar su potencial informativo sobre el poblamiento del Paleolítico medio y superior de la zona, contextualizándolos en su ámbito regional.

\section{SITUACIÓN GEOGRÁFICA}

Los yacimientos se encuentran repartidos entre los términos municipales de Vilallonga, al sur de la provincia de Valencia, y la Vall de Gallinera, al norte de la provincia de Alicante (Fig. 1). Les Majones se localiza al suroeste de Vilallonga, entre el río Serpis, al norte, y la Serra de la Safor, al sureste. La Llacuna se emplaza en el llano del mismo nombre que se extiende entre el sur del término de Vilallonga y norte del de la Vall de Gallinera, limitado al norte por la Serra de la Safor y al sur por la Serra de l'Almirant. Pla de Palau está situado entre la Serra de l'Almirant, al norte, y el río Gallinera, al sur. El espacio en que se encuentran todos estos conjuntos presenta varias sierras y valles que se extienden en sentido NE-SO, quedando enmarcado por el río Serpis al norte y el río Gallinera, de régimen discontinuo, al sur.

\section{EL CONJUNTO DE MATERIALES}

El número total de restos líticos es de 641 piezas, distribuidos de la siguiente forma: 67 proceden de Les Majones, 213 de La Llacuna, 205 de Pla de Palau y 156 de Majones-Llacuna (Fig. 2). Excepto en Les Majones, donde el lote de materiales es más reducido, en los otros tres puntos se cuenta con cantidades importantes que permiten realizar un análisis más significativo en términos cuantitativos.

Las lascas y fragmentos de lascas representan en los cuatro puntos en torno al 30-40\% del material; las hojas y fragmentos de hojas constituyen alrededor del $10 \%$ en La Llacuna y Pla de Palau, llegando al 16,67\% en Majones-Llacuna y contando con tan sólo un ejemplar en Les Majones; las hojitas y fragmentos de hojitas aparecen en porcentajes más bajos, con un único resto en Les Majones, mientras que en los tres puntos restantes representan entre el 4 y $5 \%$ de la industria; también tienen un escaso peso las lascas laminares y fragmentos de lascas laminares $(0,94 \%$ en La Llacuna y alrededor del 3\% en Pla de Palau y Majones-Llacuna); los núcleos y fragmentos de núcleos constituyen una parte destacada de los conjuntos de Les Majones, 


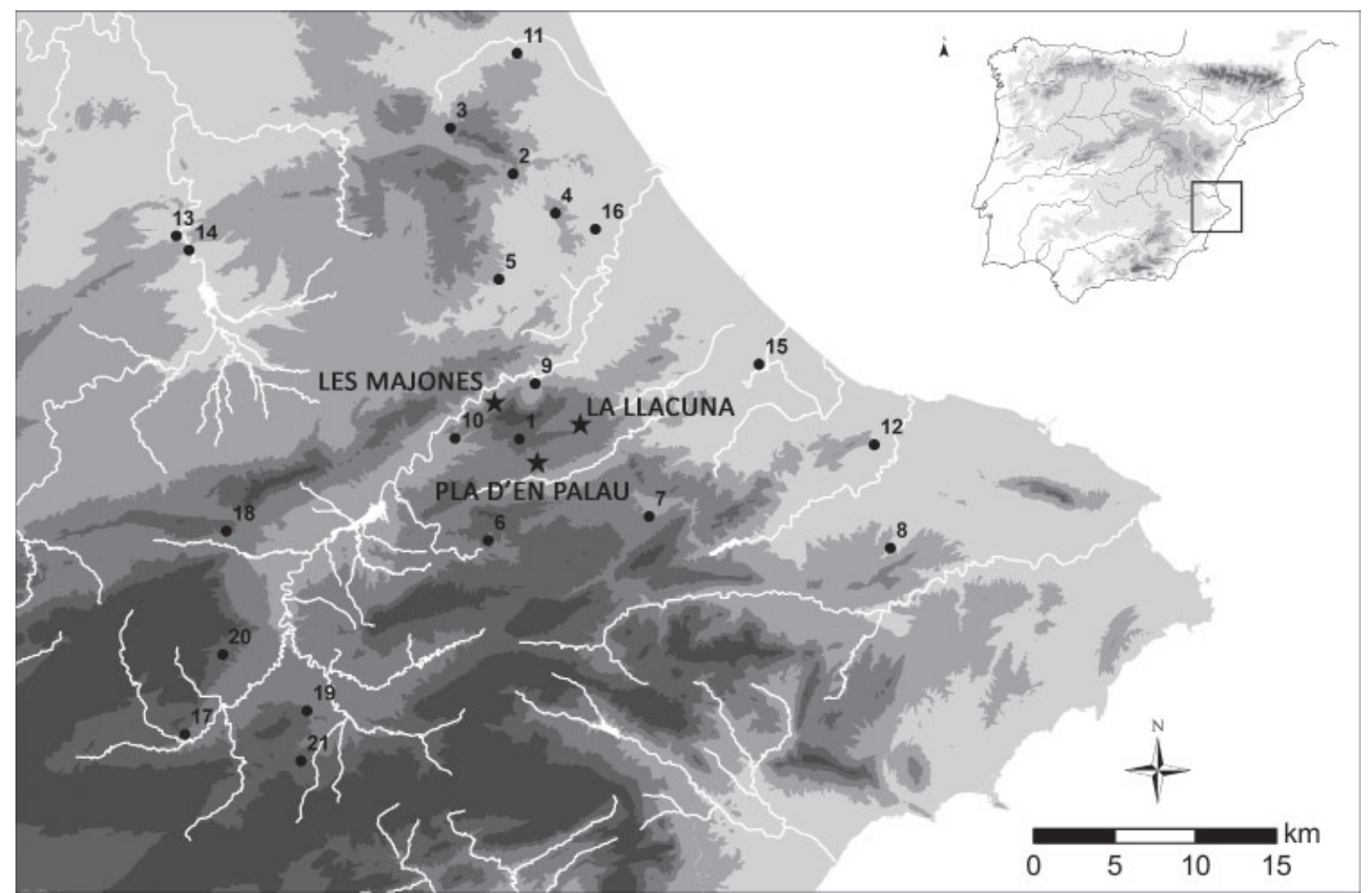

Figura 1: Plano de situación de los yacimientos estudiados y de otros mencionados en el texto: (1) Bancals de Pere Jordi, (2) Cova del Parpalló, (3) Cova de les Malladetes, (4) Cova de les Meravelles, (5) Barranc Blanc, (6) Tossal de la Roca, (7) Cova Fosca, (8) Cova del Randero, (9) Racó del Duc, (10) Cova del Gorgori, (11) Cova del Bolomor, (12) Cova del Corb, (13) Cova Negra, (14) Cova de la Petxina, (15) Cova Foradà, (16) Cova del Puntal del Gat, (17) El Salt, (18) Cova Beneito, (19) Penella, (20) Coves d'Estroig, (21) Alt de la Capella.

Pla de Palau y Majones-Llacuna (entre el 10 y el 12\% de los restos), mientras que su porcentaje es menor en La Llacuna (2,82\%); los productos de acondicionamiento de núcleo (PAN) aparecen en porcentajes bajos en todos los puntos y en Les Majones ni siquiera se documentan; también se cuenta con un canto sobre el que se ha fabricado un útil en Pla de Palau y un golpe de buril en Majones-Llacuna; finalmente destacar que el conjunto de indeterminados (esquirlas, informes

\begin{tabular}{|c|c|c|c|c|c|}
\cline { 2 - 6 } & $\begin{array}{c}\text { Les } \\
\text { Majones }\end{array}$ & La Llacuna & Pla de Palau & $\begin{array}{c}\text { Majones- } \\
\text { Ulacuna }\end{array}$ & Total \\
\hline $\begin{array}{c}\text { Lascas y frag. } \\
\text { lascas }\end{array}$ & $20(29,85 \%)$ & $75(35,21 \%)$ & $86(41,95 \%)$ & $57(36,54 \%)$ & 238 \\
\hline $\begin{array}{c}\text { Hojas y frag. } \\
\text { hojas }\end{array}$ & $1(1,49 \%)$ & $25(11,74 \%)$ & $22(10,73 \%)$ & $26(16,67 \%)$ & 72 \\
\hline $\begin{array}{c}\text { Hojitasy } \\
\text { frag. hojitas }\end{array}$ & $1(1,49 \%)$ & $7(3,29 \%)$ & $10(4,88 \%)$ & $7(4,49 \%)$ & 27 \\
\hline $\begin{array}{c}\text { Lascas lam. y } \\
\text { frag. lascas } \\
\text { lam. }\end{array}$ & 0 & $2(0,94 \%)$ & $6(2,93 \%)$ & $5(3,21 \%)$ & 13 \\
\hline $\begin{array}{c}\text { Núcleosy } \\
\text { frag. núcleos }\end{array}$ & $7(10,45 \%)$ & $6(2,82 \%)$ & $24(11,71 \%)$ & $18(11,54 \%)$ & 55 \\
\hline PAN & 0 & $6(2,82 \%)$ & $7(3,41 \%)$ & $4(2,56 \%)$ & 17 \\
\hline Canto & 0 & 0 & $1(0,49 \%)$ & 0 & 1 \\
\hline $\begin{array}{c}\text { Golpe de } \\
\text { Buril }\end{array}$ & 0 & 0 & 0 & $1(0,64 \%)$ & 1 \\
\hline Indet. & $38(56,72 \%)$ & $92(43,19 \%)$ & $49(23,90 \%)$ & $38(24,36 \%)$ & 217 \\
\hline Total & 67 & 213 & 205 & 156 & 641 \\
\hline
\end{tabular}

Figura 2: Soportes documentados en los yacimientos. y fragmentos de lasca térmica), excluido del estudio pormenorizado de los materiales, constituye entre el 20 y $25 \%$ del total en Pla de Palau y Majones-Llacuna, alcanzando el $43,19 \%$ en La Llacuna y el $56,72 \%$ en Les Majones.

Como se aprecia en la Figura 3, en función de los restos de los cuales se ha podido determinar la cronología, se cuenta con 227 piezas del Paleolítico medio y 201 del Paleolítico superior. La representación de ambos periodos en cada uno de los cuatro conjuntos es bastante equilibrada, aunque los restos del Paleolítico medio siempre superan ligeramente a los del Paleolítico superior. Para identificar las piezas del Paleolítico medio se han seguido criterios tecno-tipológicos como la presencia de soportes producidos mediante el método Levallois o de útiles, sobre todo producto de tallas de tipo discoide, característicos de este periodo (raederas, puntas o cuchillos de dorso natural). Tecnológicamente, la gestión Levallois de los soportes se

\begin{tabular}{|c|c|c|c|c|c|}
\cline { 2 - 6 } \multicolumn{1}{c|}{} & $\begin{array}{c}\text { Les } \\
\text { Majones }\end{array}$ & La Llacuna & Pla de Palau & $\begin{array}{c}\text { Majones- } \\
\text { Ulacuna }\end{array}$ & Total \\
\hline $\begin{array}{c}\text { Paleolítico } \\
\text { medio }\end{array}$ & 20 & 65 & 82 & 60 & 227 \\
\hline $\begin{array}{c}\text { Paleolítico } \\
\text { superior }\end{array}$ & 9 & 59 & 74 & 59 & 201 \\
\hline
\end{tabular}

Figura 3: Adscripción cronológica de los materiales. 
1

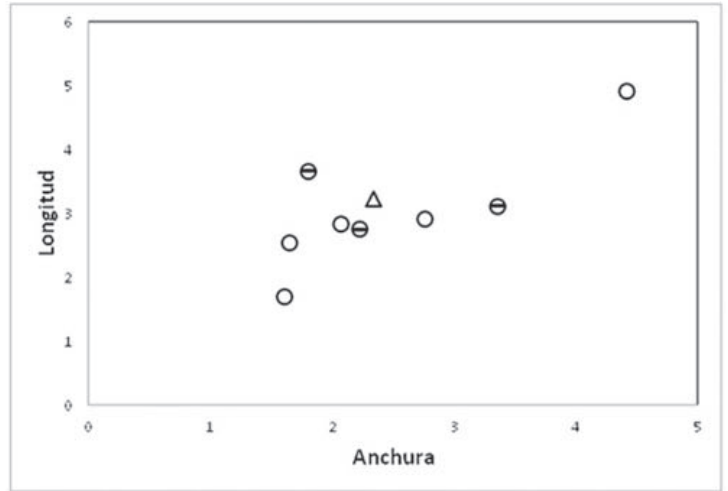

2

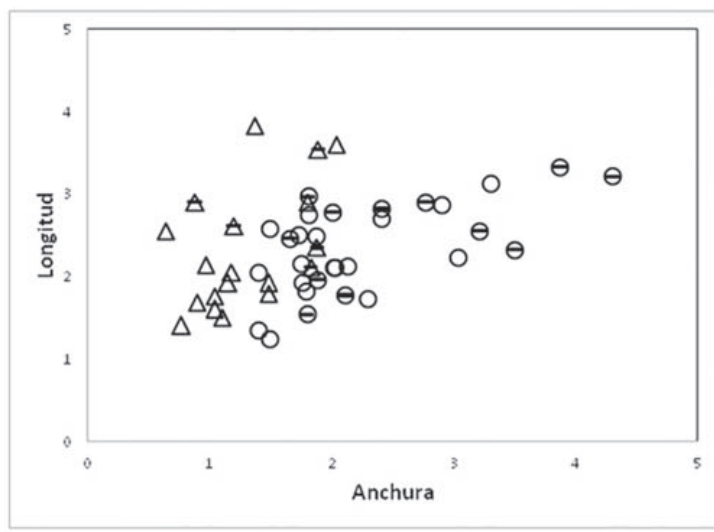

3

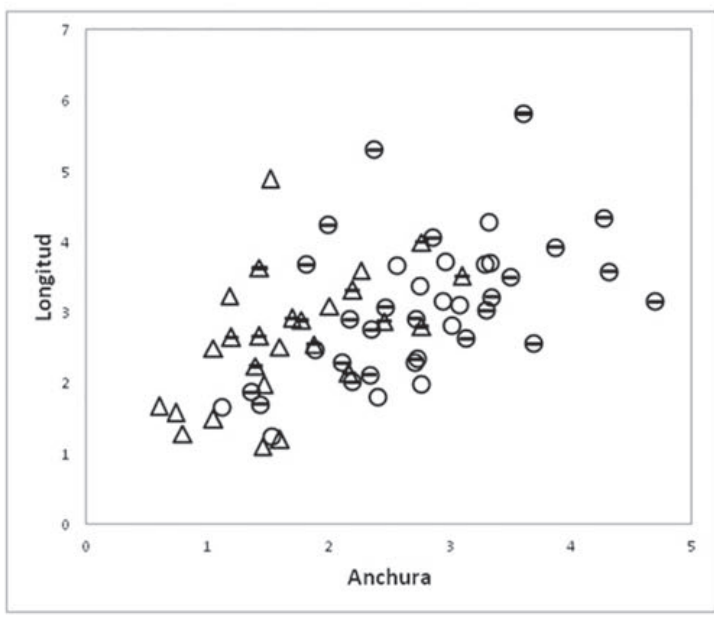

4

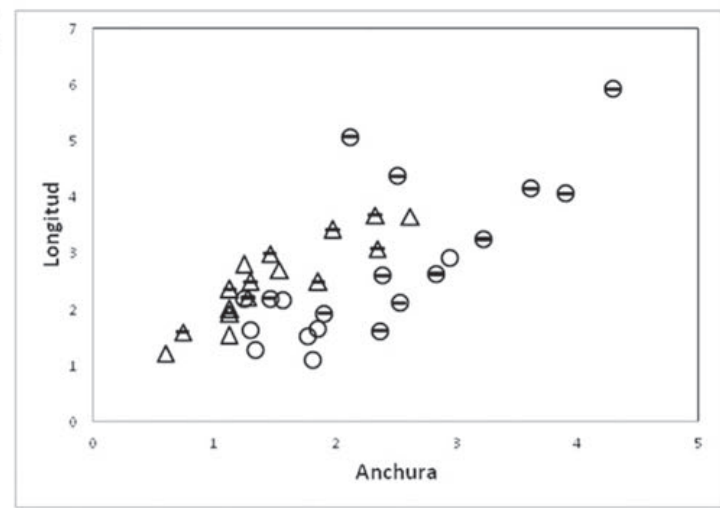

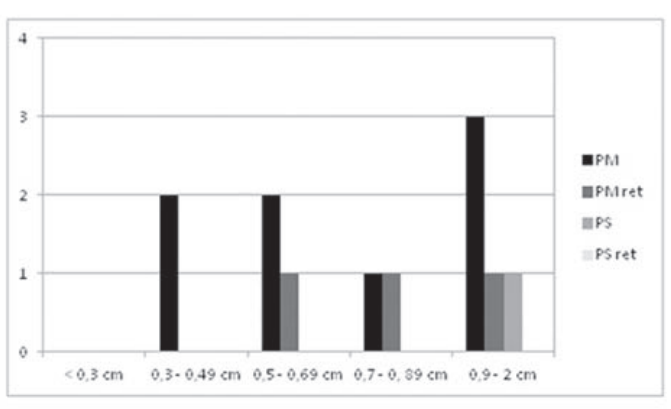
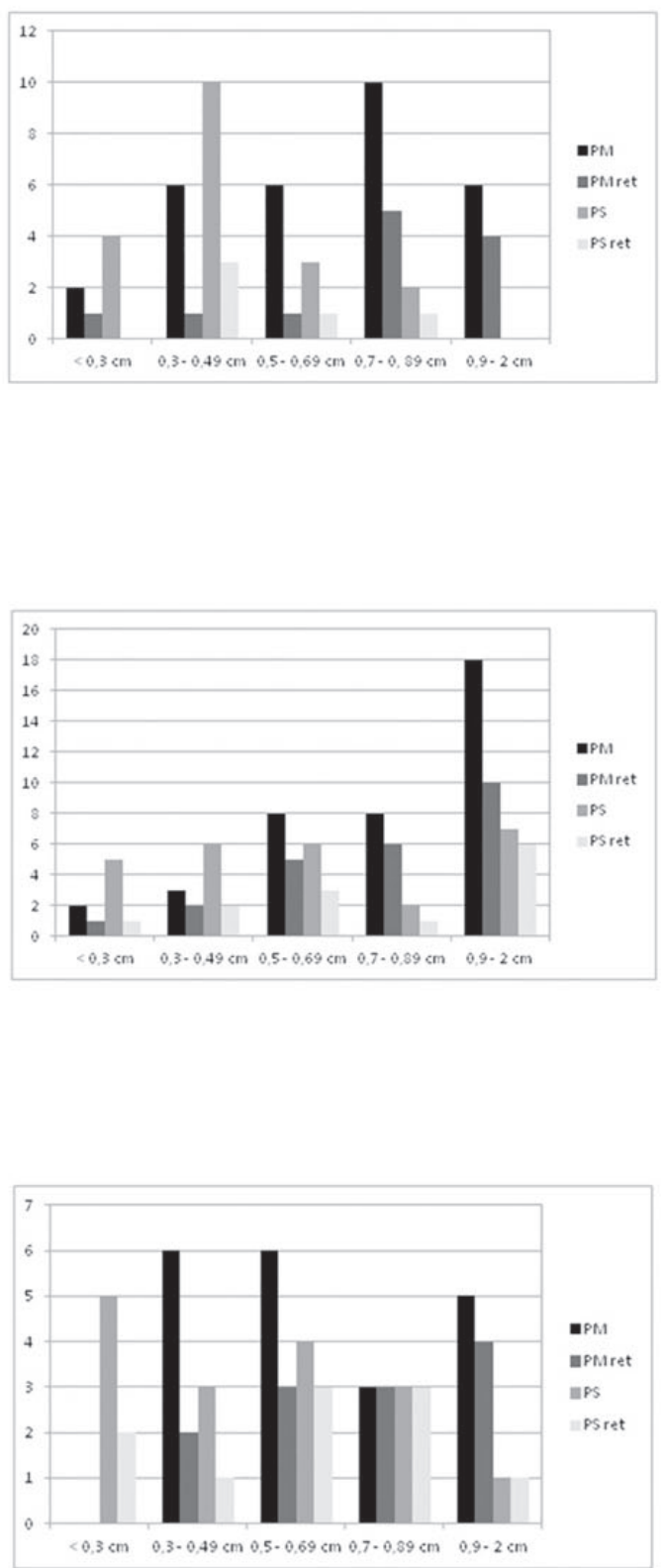

OPaleolitico medio $\triangle$ Paleolitico superior $\quad-$ Retocado

Figura 4: Distribución de la longitud, anchura y espesor de los materiales documentados en los yacimientos: 1. Les Majones, 2. La Llacuna, 3. Pla de Palau, 4. Majones-Llacuna. 
caracteriza por presentar una morfología regular, con un eje de simetría longitudinal y en los que el contorno de la lasca es cortante y la cara dorsal presenta varios negativos relacionados con la preparación de la superficie de lascado (convexidades lateral y distal). En los soportes secundarios, la cara superior presenta, además, uno o más negativos invasores interpretados como levantamientos obtenidos en fases anteriores (método recurrente). A estos criterios, se puede añadir también la presencia de talones facetados (Boëda et alii, 1990; Boëda, 1994). En la talla discoide se han incluido los productos del lascado gruesos, con talones lisos, secciones disimétricas y frecuentemente desbordantes y/o corticales, producto de tallas centrípetas y cordales que se traducen con frecuencia en los típicos elementos de morfología pseudolevallois (Boëda, 1993; Mourre, 2003; Slimak, 2003). Los materiales del Paleolítico superior se han identificado a partir de criterios como la presencia de soportes laminares (hojas y hojitas) o de útiles típicos de este periodo (raspadores, buriles, piezas astilladas o foliáceos). En el análisis tipométrico que sigue se han diferenciado los materiales del Paleolítico medio de los del Paleolítico superior, dada la distinta morfología de muchos de los soportes en cada periodo.

La longitud de buena parte de los soportes del $\mathrm{Pa}$ leolítico medio se encuentra entre los 2 y $3 \mathrm{~cm}$ en los cuatro lugares estudiados, aunque en Pla de Palau también hay una buena proporción de restos que tiende a medir entre 3 y $4 \mathrm{~cm}$, mientras que en La Llacuna y Majones-Llacuna hay un número destacado de piezas entre 1,5 y $2 \mathrm{~cm}$ (Fig. 4). Además en Pla de Palau y Majones-Llacuna hay algunas piezas con una longitud superior a los $4 \mathrm{~cm}$, casi todas retocadas. En cuanto a la anchura, la mayoría de piezas se encuentra entre 1,5 y $3 \mathrm{~cm}$, aunque en Pla de Palau también son abundantes las piezas de entre 3 y $4 \mathrm{~cm}$. El espesor varía de un sitio a otro: en Les Majones y Pla de Palau predominan las piezas de entre 0,9 y $2 \mathrm{~cm}$, en La Llacuna las de entre 0,7 y 0,89 cm, mientras que en Majones-Llacuna destacan las piezas de los intervalos $0,3-0,49 \mathrm{~cm}$ y $0,5-0,69 \mathrm{~cm}$, del mismo modo que piezas con estos espesores reducidos también aparecen en cantidades importantes en La Llacuna.

En lo referente a los restos del Paleolítico superior, su longitud es más variable, con medidas de entre 1 y $4 \mathrm{~cm}$, aunque el grueso del material se encuentra entre 1 y $3 \mathrm{~cm}$ (Fig. 4). En cuanto a la anchura la mayoría se encuentran entre 0 y $2 \mathrm{~cm}$, en gran parte debido a la importante proporción de soportes laminares ${ }^{1}$. El espesor es generalmente menor que el de los soportes de Paleolítico medio, con abundante presencia de

1. En este trabajo la medida de distinción entre hojas y hojitas se ha fijado en $0,8 \mathrm{~cm}$ de anchura, como se ha planteado para los conjuntos de la región teniendo en cuenta sus características tipométricas habituales (Román, 2004; Villaverde et alii, 2012b). piezas menores de $0,7 \mathrm{~cm}$ tanto en La Llacuna como en Majones-Llacuna y predominando los espesores de entre 0,9 y $2 \mathrm{~cm}$ tan sólo en Pla de Palau.

Nos encontramos ante una industria de reducido tamaño en los cuatro conjuntos en lo que se refiere al Paleolítico medio, de entre los que destaca Pla de Palau con las mayores dimensiones. Resulta interesante constatar la presencia de algunas piezas inferiores a los $2 \mathrm{~cm}$ tanto en longitud como en anchura, bien sea por la importancia de estos formatos en los conjuntos valencianos del Paleolítico medio (Villaverde, 1984; Iturbe et alii, 1993; Fernández Peris, 2007; Galván et alii, 2009; Villaverde et alii, 2012a), por un mayor cuidado en algunas recogidas del material o por ambos motivos. Las piezas del Paleolítico superior presentan unas dimensiones generalmente más reducidas que las del Paleolítico medio, si bien las igualan o incluso superan en longitud en numerosos casos como consecuencia de los soportes laminares.

\section{MATERIAS PRIMAS}

Casi la totalidad de las piezas analizadas se han realizado sobre sílex, aunque también se cuenta con una cuarcita en Pla de Palau y una caliza en MajonesLlacuna. La fuerte preponderancia de esta litología es coherente con el hecho de que en la mayoría de yacimientos del País Valenciano resulta la materia prima más explotada, como se ha destacado especialmente en yacimientos del Paleolítico medio (Molina et alii, 2010; Eixea et alii, 2011). No obstante, la casi total ausencia de otras litologías también puede deberse a un sesgo en la recogida del material.

Se han identificado dos tipos de sílex que se corresponden básicamente con los ya planteados en el artículo anterior sobre el conjunto de Els Bancals de Pere Jordi (Eixea y Villaverde, 2012), al que remitimos para su caracterización. En el conjunto de los cuatro sitios estudiados el Tipo 1 (sílex de grano fino) representa el $47,18 \%$ de los materiales y el Tipo 2 (grano grueso) el $3,99 \%$, mientras que un $48,36 \%$ de las piezas se encuentran patinadas y deshidratadas por completo como resultado de su exposición a la intemperie, por lo que no ha sido posible la determinación del tipo de sílex. Conviene destacar que tan sólo en Pla de Palau el número de restos con estas alteraciones postdeposicionales supera a los que sí han podido caracterizarse a nivel de tipo de sílex, mientras que en los tres conjuntos restantes las piezas con alteraciones se mantienen en cantidades próximas a las de los restos de los que sí se conoce el tipo.

\section{ANÁLISIS TECNOLÓGICO}

En los cuatro conjuntos se reconocen distintos sistemas de talla teniendo en cuenta tanto los soportes como los núcleos. El más representado es el sistema 


\begin{tabular}{|c|c|c|c|c|c|}
\cline { 2 - 6 } \multicolumn{1}{c|}{} & $\begin{array}{c}\text { Les } \\
\text { Majones }\end{array}$ & La Llacuna & Pla de Palau & $\begin{array}{c}\text { Majones- } \\
\text { Ulacuna }\end{array}$ & Total \\
\hline Discoide & $6(22,22 \%)$ & $33(26,4 \%)$ & $43(28,67 \%)$ & $32(26,02 \%)$ & $114(26,82 \%)$ \\
\hline $\begin{array}{c}\text { Levallois } \\
\text { recurrente } \\
\text { centripeto }\end{array}$ & $1(3,70 \%)$ & $8(6,4 \%)$ & $12(8 \%)$ & $3(2,44 \%)$ & $24(5,65 \%)$ \\
\hline $\begin{array}{c}\text { Levallois } \\
\text { preferencial }\end{array}$ & $1(3,70 \%)$ & $1(0,8 \%)$ & $3(2 \%)$ & $1(0,81 \%)$ & $6(1,41 \%)$ \\
\hline Kombewa & 0 & $2(1,6 \%)$ & $2(1,33 \%)$ & $2(1,63 \%)$ & $6(1,41 \%)$ \\
\hline Laminar & $6(22,22 \%)$ & $45(36 \%)$ & $51(34 \%)$ & $51(41,46 \%)$ & $153(36 \%)$ \\
\hline Façonnage & 0 & 0 & $1(0,67 \%)$ & 0 & $1(0,23 \%)$ \\
\hline Indet. & $13(48,15 \%)$ & $36(28,8 \%)$ & $38(25,33 \%)$ & $34(27,64 \%)$ & $121(28,47 \%)$ \\
\hline Total & 27 & 125 & 150 & 123 & 425 \\
\hline
\end{tabular}

Figura 5: Sistemas de talla empleados en los yacimientos. de talla laminar, con porcentajes que oscilan entre el 34 y el $41 \%$, sólo descendiendo al $22 \%$ en Les Majones, hecho que reafirma la importancia de las piezas del Paleolítico superior en estos conjuntos. A este le siguen el método discoide (22-29\%), el Levallois recurrente centrípeto (2-8\%), el Levallois de lasca preferencial (1-4\%), el Kombewa (1-2\%) y un útil (bifaz) realizado mediante el sistema del façonnage. Además las piezas de las que no se ha podido determinar el sistema de talla representan entre el 25 y $28 \%$, a excepción del conjunto de Les Majones donde constituyen casi la mitad de los restos (Fig. 5).

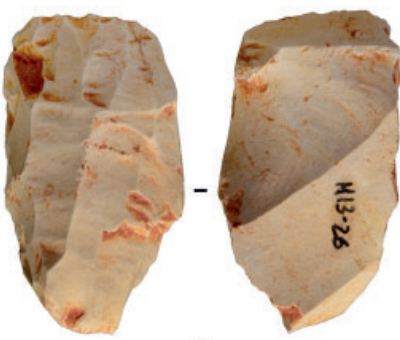

1

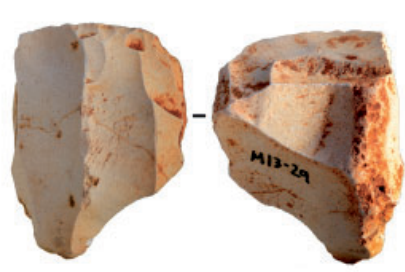

4

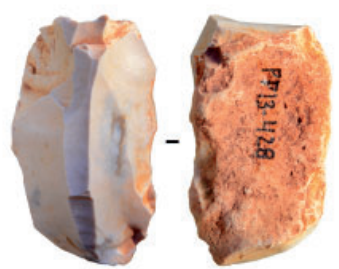

8
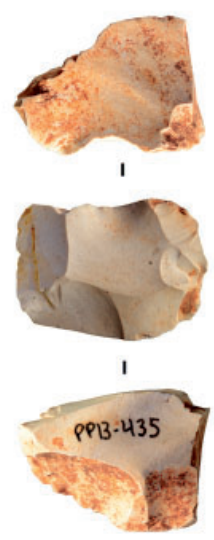

13

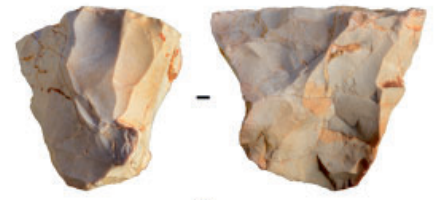

9

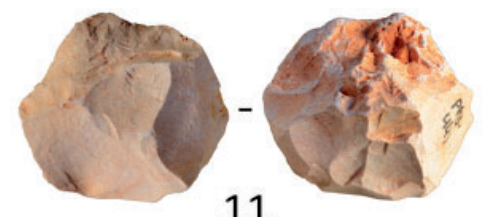

11

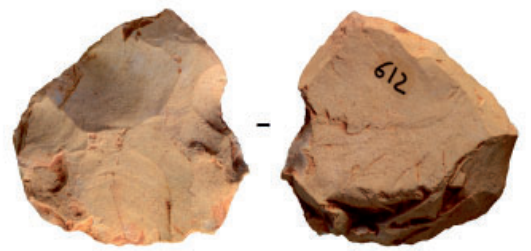

14

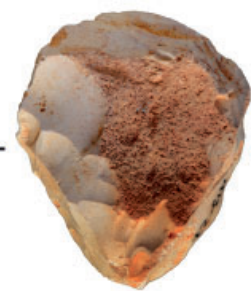

2

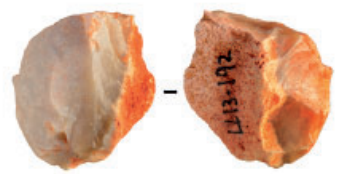

6

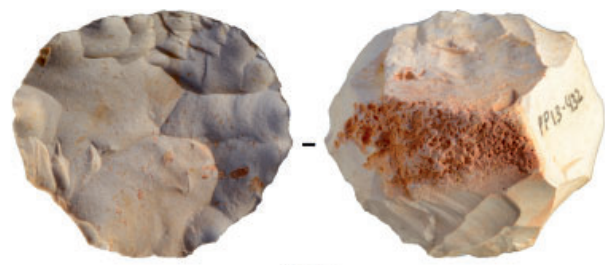

10

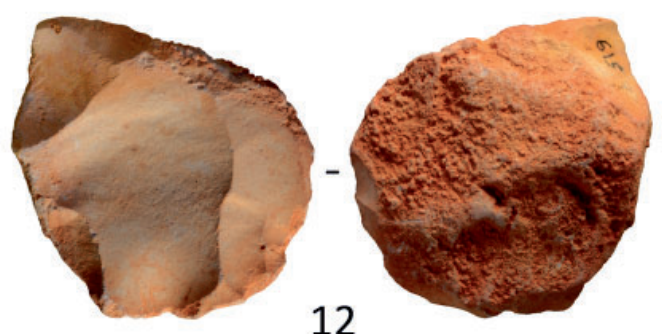

12

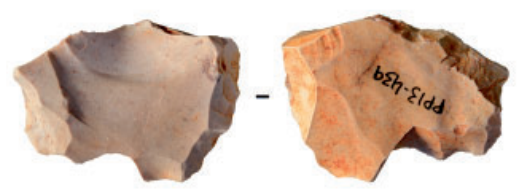

15

Figura 6: Núcleos del Paleolítico superior. Laminar unipolar: 1 (M); 8 y 9 (PP). Laminar bipolar: 2, 3 y 4 (M); 5 y 6 (LL); 7 (M-LL). Núcleos del Paleolítico medio. Levallois recurrente de lascas centrípetas: 10 (PP); 14 (M-LL). Discoide unifacial: 11 (PP). Levallois de lasca preferencial: 12 (M-LL); 15 (PP). Quina: 13 (PP). (Yacimientos: M - Les Majones, LL - La Llacuna, PP - Pla de Palau, M-LL Majones-Llacuna) (Fotografías: V. Villaverde, M.A. Bel y A. Eixea). 
En la mayor parte de los casos la técnica empleada es la percusión con percutor duro, aunque la importancia de los restos laminares del Paleolítico superior evidencia cierto peso de la percusión con percutor blando.

\subsection{TALLA LAMINAR}

El sistema de talla laminar cuenta con 153 restos (36\%), entre los que hay 31 núcleos de los cuales 7 son fragmentos (la mayoría de estos procedentes de Majones-Llacuna), distribuidos entre los cuatro lugares estudiados y que constituyen más de la mitad de los núcleos documentados (Fig. 6). Son núcleos en sílex, generalmente prismáticos y se dividen entre los de explotación unipolar (16) y los de bipolar (15), destinados a la producción de hojas y hojitas durante el Paleolítico superior. La mayoría presenta longitudes comprendidas entre los 2 y $4 \mathrm{~cm}$, anchuras entre $1,5 \mathrm{y}$ $3,5 \mathrm{~cm}$ y espesores entre 1 y 2,5 cm; son por lo tanto de dimensiones reducidas y morfología alargada producto de la talla laminar. Predominan claramente los núcleos sobre nódulo con 21 efectivos, mientras que hay 8 sobre lasca (la mitad en Majones-Llacuna) y 2 de los que no se ha podido identificar el soporte debido a las fracturas; además casi la mitad presentan superficies corticales, predominando entre estas las que ocupan menos del 20\% de la pieza (8). En cuanto a las superficies de explotación, la curvatura es predominantemente convexa (20) y la forma rectangular ancha (20). La longitud de las últimas extracciones es muy variable, desde $0,63 \mathrm{~cm}$ hasta $3,44 \mathrm{~cm}$, mientras que la anchura oscila entre 0,2 y $1,4 \mathrm{~cm}$, con 13 núcleos cuya última extracción es microlaminar. La mayoría de los núcleos se encuentran en fase de plena producción (21), mientras que hay uno abandonado por error de talla y otro por defecto del material, así como tres agotados.

En relación a los soportes laminares se distinguen 37 talones lisos (casi la mitad en Majones-Llacuna), 3 lineales (dos en La Llacuna), 2 diedros, 1 cortical, 7 suprimidos, 13 rotos y 42 restos sin talón debido a una fractura. La escasez de talones lineales y diedros, así como la total ausencia de facetados, evidencian la poca preparación de los puntos de percusión. A excepción de cuatro restos dudosos, todos pertenecen a la fase de plena explotación. En cuanto a las superficies corticales, contamos con 19 piezas de segundo orden y 86 de tercer orden. Cabe destacar que entre las hojas y hojitas 42 son de sección triangular y 35 de sección trapezoidal. En los soportes del Paleolítico superior también deben incluirse los productos de acondicionamiento del núcleo (PAN), generados durante la reconfiguración de los núcleos para mejorar las plataformas de percusión y superficies de explotación. Contamos con 2 crestas y 5 semicrestas, 8 semitabletas y 2 aristas laterales. Estos presentan 7 talones lisos, 1 lineal, 2 suprimidos, 2 rotos y 5 sin talón por fractura. Corresponden a la fase de mantenimiento, si bien hay 4 de estos productos que han sido reaprovechados para realizar útiles y por lo tanto se encuentran en la fase de plena explotación. En cuanto al orden, excepto dos restos de segundo orden, todos son de tercer orden.

El material retocado está compuesto por 48 piezas del total de restos laminares (Figs. 7 y 8). Predominan los raspadores, con 15 efectivos, de entre los cuales hay 5 simples y 5 sobre hoja retocada. Los buriles son más escasos (4) y dos de ellos componen útiles dobles junto a frentes de raspador. Entre el utillaje de dorso (4) destacan dos hojitas de dorso apuntadas, ambas de Pla de Palau. También se cuenta con 4 piezas astilladas (repartidas entre La Llacuna y Majones-Llacuna) y 3 que presentan alguna muesca. Además 6 piezas presentan claras macrohuellas de uso. Destaca la presencia de dos fragmentos de puntas sobre cara plana en Pla de Palau, así como de dos fragmentos de foliáceos bifaciales, uno de ellos de ese mismo lugar y definido claramente como hoja de laurel.

\subsection{TALLA DISCOIDE}

El segundo sistema de talla más representado es el discoide, que cuenta con 114 restos $(26,82 \%)$, de los cuales 6 son núcleos (Fig. 6), con tan sólo uno de estos fracturado. Todos los núcleos son de sílex, tres procedentes de Pla de Palau y con un sistema de explotación unifacial, mientras que los tres restantes proceden de Majones-Llacuna y presentan una explotación bifacial. En general la longitud se encuentra en torno a los 2,5 y $3,5 \mathrm{~cm}$, la anchura entre los 3 y $4 \mathrm{~cm}$ y el espesor de 1 a $2 \mathrm{~cm}$ (a excepción de un núcleo en Majones-Llacuna con un espesor de $3,11 \mathrm{~cm}$ ); núcleos de dimensiones reducidas y con una morfología que lleva a que todas las superficies de talla sean de carácter rectangular ancho (exceptuando el fragmento de núcleo, con superficie rectangular estrecha). En cuanto al soporte, siguen predominando los nódulos (4) por encima de las lascas (2, ambas en Pla de Palau); a excepción de un núcleo sin córtex, todos presentan superficies corticales en mayor o menor medida. La curvatura de la superficie de explotación es plana ( 3 , dos casos en Pla de Palau) o convexa (3, dos casos en Majones-Llacuna). La longitud de las últimas extracciones se encuentra en torno a 1-2 cm, mientras que la anchura oscila entre 1 y $3 \mathrm{~cm}$. En cuanto al estado de los núcleos todos se encuentran en fase de plena producción a excepción de uno que está agotado. Se evidencia así el reducido tamaño de los soportes producidos con este sistema de talla, tamaño que concuerda con lo visto en algunos yacimientos del País Valenciano (Villaverde et alii, 2012a).

Los soportes presentan morfologías cuadrangulares, formatos disimétricos y espesos (un tercio de los productos completos por encima de $1 \mathrm{~cm}$ ), con una explotación centrípeta del que son un reflejo particular los productos desbordantes y de tipo pseudolevallois (7). Hay 63 talones lisos, 2 diedros, 1 facetado 


\begin{tabular}{|c|c|c|c|c|c|}
\hline & $\begin{array}{l}\text { Les } \\
\text { Majones }\end{array}$ & La Llacuna & Pla de Palau & $\begin{array}{l}\text { Majones- } \\
\text { Llacuna }\end{array}$ & Total \\
\hline \multicolumn{6}{|l|}{ PALEOLÍTICO MEDIO } \\
\hline \multicolumn{6}{|l|}{ Raederas } \\
\hline simple & 3 & 7 & 7 & 1 & 18 \\
\hline doble & & & & 5 & 5 \\
\hline alterna & & & 3 & 1 & 4 \\
\hline convergente & & & 1 & & 1 \\
\hline desviada & & 1 & 1 & 1 & 3 \\
\hline transversal & & 2 & 1 & & 3 \\
\hline sobre cara plana & 1 & 2 & 1 & & 4 \\
\hline \multicolumn{6}{|l|}{ Muescas y denticulados } \\
\hline Denticulado & 1 & 1 & 1 & 5 & 8 \\
\hline Muesca & & 3 & 5 & 3 & 11 \\
\hline \multicolumn{6}{|l|}{ Grupo Levallois } \\
\hline Lasca Levallois atípica & & 2 & 4 & & 6 \\
\hline Punta Levallois & & 1 & & & 1 \\
\hline Punta Pseudolevallois & & & 1 & & 1 \\
\hline Punta musteriense & & & 1 & & 1 \\
\hline Cuchillo de dorso atípico & & & 1 & & 1 \\
\hline Cuchillo de dorso natural & & 2 & 7 & 2 & 11 \\
\hline Perforador & & 1 & & 1 & 2 \\
\hline Bifaz & & & 1 & & 1 \\
\hline Pieza con huellas de uso & & 1 & 2 & 1 & 4 \\
\hline Diversos & & & & & \\
\hline Raedera doble - Perforador & & & 1 & & 1 \\
\hline Total & 5 & 23 & 38 & 20 & 86 \\
\hline \multicolumn{6}{|l|}{ PALEOLITICO SUPERIOR } \\
\hline \multicolumn{6}{|l|}{ Raspadores } \\
\hline Raspador simple & & 2 & 8 & 3 & 13 \\
\hline Raspador atípico sobre lámina & & 1 & & & 1 \\
\hline Raspador ojival & & & 1 & & 1 \\
\hline Raspador sobre lámina retocada & & 1 & & 4 & 5 \\
\hline Raspador sobre lasca retocada & & 1 & & & 1 \\
\hline \multicolumn{6}{|l|}{ Compuestos } \\
\hline Buril - Raspador & & & 1 & 1 & 2 \\
\hline Buriles & & 1 & 1 & 1 & 3 \\
\hline Punta de dorso & & 1 & & & 1 \\
\hline \multicolumn{6}{|l|}{ Truncaduras } \\
\hline Lámina o lasca con truncadura & & & 2 & & 2 \\
\hline \multicolumn{6}{|l|}{$\begin{array}{l}\text { Piezas con retoques en los } \\
\text { bordes }\end{array}$} \\
\hline $\begin{array}{l}\text { Lámina o lasca con retoques } \\
\text { continuos en un borde }\end{array}$ & & & & 4 & 4 \\
\hline $\begin{array}{l}\text { Lámina o lasca con retoques } \\
\text { parciales en un borde }\end{array}$ & & 2 & 1 & & 3 \\
\hline \multicolumn{6}{|l|}{ Foliáceos } \\
\hline Punta de cara plana & & & 2 & & 2 \\
\hline Hoja de laurel & 1 & & 1 & & 2 \\
\hline $\begin{array}{c}\text { Foliáceo (Solutrense o } \\
\text { Calcolítico) }\end{array}$ & & 1 & & & 1 \\
\hline \multicolumn{6}{|l|}{ Muescas y denticulados } \\
\hline Muesca & & 1 & 2 & & 3 \\
\hline Pieza astillada & & 2 & 2 & 3 & 7 \\
\hline \multicolumn{6}{|l|}{ Microlaminar } \\
\hline Laminita de dorso & & 1 & & 1 & 2 \\
\hline Laminita de dorso apuntada & & & 2 & & 2 \\
\hline $\begin{array}{l}\text { Laminita de finos retoques } \\
\text { directos }\end{array}$ & & & & 1 & 1 \\
\hline $\begin{array}{l}\text { Laminita con finos retoques } \\
\text { inversos }\end{array}$ & & & & 1 & 1 \\
\hline Fragmento de pieza retocada & & 2 & & & 2 \\
\hline Pieza con huellas de uso & 1 & 1 & 5 & 1 & 8 \\
\hline Total & 2 & 17 & 28 & 20 & 67 \\
\hline
\end{tabular}

Figura 7: Tipos líticos del Paleolítico medio y del Paleolítico superior. 


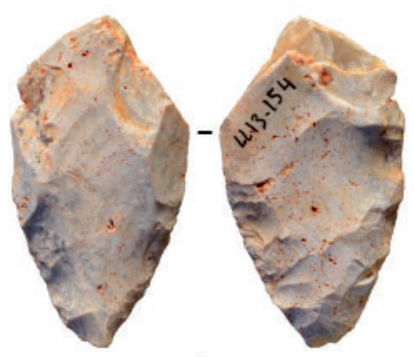

1

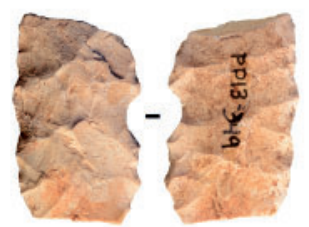

6

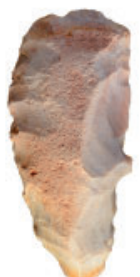

12

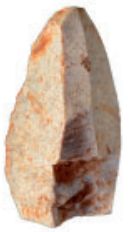

20

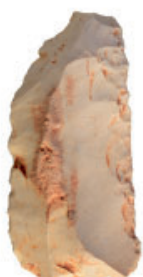

13

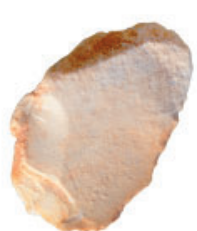

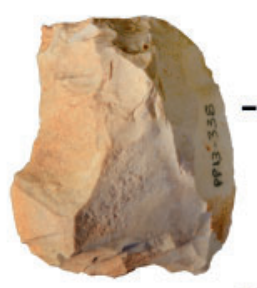

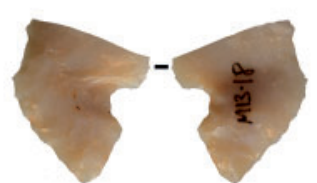

7
2
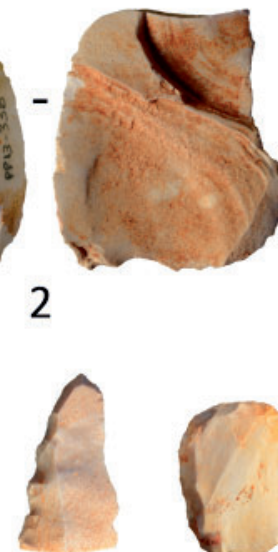

8

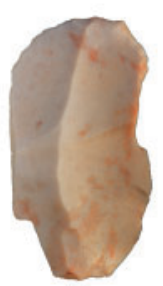

3

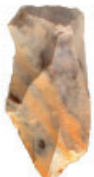

10

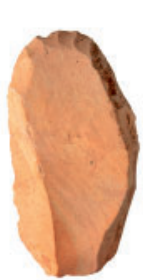

4

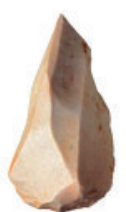

11

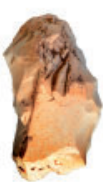

18

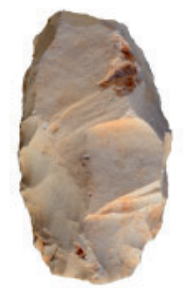

5
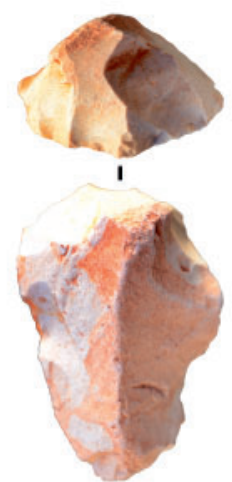

19

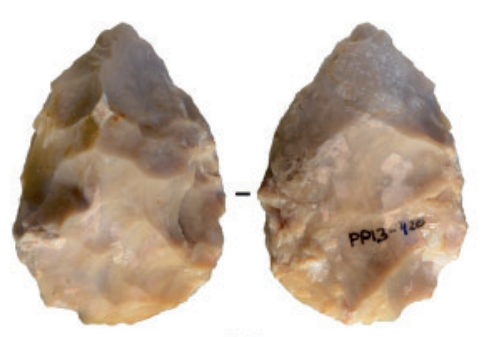

29

14

15
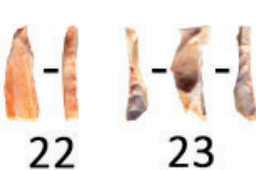

23

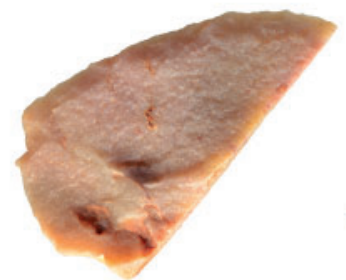

30

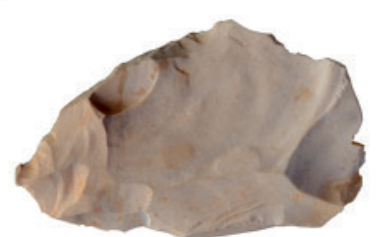

31

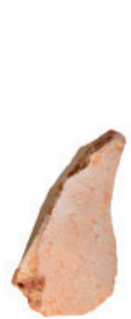

27

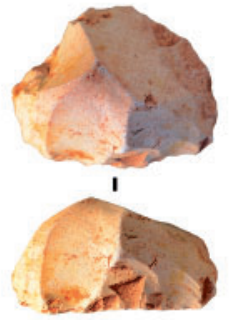

28

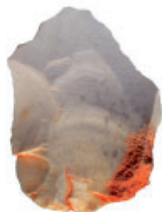

33

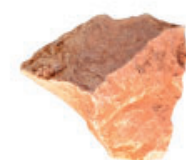

34

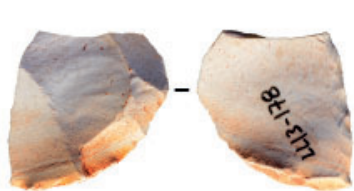

35

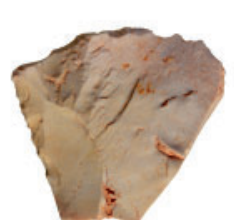

36

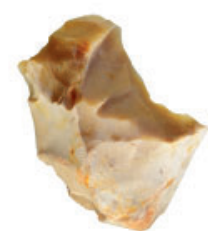

37

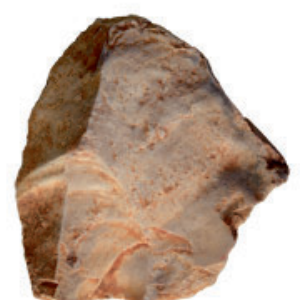

32

Figura 8: Material del Paleolítico superior. Foliáceo: 1 (LL), 6 (PP) y 7 (M). Pieza astillada: 2 (PP). Raspador: 3,14 y 17 (LL); 18,19 y 28 (PP). Raspador sobre lasca/hoja retocada: 9 y 10 (LL); 5, 15 y 16 (M-LL). Raspador sobre semitableta: 4 (PP). Raspador-buril: 11 (PP). Punta de dorso: 8 (LL). Punta de cara plana: 13 (PP). Hojita de dorso: 22 y 23 (PP); 24 (LL). Pieza astillada sobre arista de núcleo: 25 (M-LL). Cresta: 26 (PP). Semitableta: 27 (PP). Material del Paleolítico medio. Punta Levallois: 20 (LL). Cuchillo de dorso natural: 21 (LL). Bifaz: 29 (PP). Raedera doble recto-convexa y perforador: 12 (PP). Raedera alterna: 30 (PP). Raedera simple convexa: 31 (PP). Raedera sobre cara plana: 35 (LL). Raedera simple recta opuesta a meplat: 36 (PP). Perforador: 37 (LL). Punta pseudolevallois: 34 (PP). Muesca sobre lasca pseudolevallois: 38 (PP). Lasca Levallois atípica: 32 (PP); 33 (LL). (Yacimientos: M - Les Majones, LL - La Llacuna, PP - Pla de Palau, M-LL - Majones-Llacuna) (Fotografías: V. Villaverde, M.A. Bel y A. Eixea). 
convexo, 7 corticales (la mayoría de La Llacuna), 1 machacado, 1 suprimido, 5 rotos y 28 sin talón por fractura. Como ya se ha apuntado para la talla laminar, se aprecia que la preparación de los puntos de percusión no es importante, con un amplio predominio de los talones lisos. Aunque la gran mayoría de los restos corresponde a la fase de plena explotación, también contamos con dos dudosos y ocho de inicio de explotación. No obstante, la proporción de piezas con superficies corticales es importante (la mayoría inferiores al $20 \%$ ), con 44 restos de segundo orden frente a 64 de tercer orden.

La talla discoide presenta 55 piezas retocadas. Los útiles mejor representados son las raederas (24) (Fig. 7), características de los conjuntos musterienses, entre las que destacan las simples convexas (10), con dos de ellas opuestas a meplat y una a dorso natural, del mismo modo que cuatro se han clasificado como semiquina en función de su espesor y el retoque escaleriforme que presentan (Fig. 8). A estas les siguen las raederas alternas (4) (tres de las cuales procedentes de Pla de Palau) con una de ellas al límite con el denticulado y otra clasificada como semiquina, las simples rectas (3) (todas de Pla de Palau) con dos de ellas opuestas a dorso y/o meplat, las dobles (3) (todas de MajonesLlacuna), las transversales (2) (ambas de La Llacuna), las desviadas (1) y las raederas sobre cara plana (1). El grupo de las piezas con muescas (10) y los denticulados (3) supone una porción destacada del conjunto de soportes retocados. Los cuchillos de dorso natural están representados por 8 efectivos, junto con un cuchillo atípico y uno opuesto a meplat (estas dos últimas y la mitad de los cuchillos de dorso natural proceden de Pla de Palau). Además hay tres piezas con huellas de uso, una de ellas una punta pseudolevallois, y dos perforadores. Por último conviene señalar la presencia de tres útiles del Paleolítico superior, dos raspadores y una pieza astillada, realizados sobre lascas discoides.

\subsection{TALLA LEVALLOIS}

En lo referente al método de talla Levallois, se cuenta con 30 restos, 24 pertenecientes al sistema Levallois de lascas recurrentes centrípetas $(5,65 \%)$ y 6 al $L e$ vallois de lasca preferencial $(1,41 \%)$. En el primero hay 6 núcleos (Fig. 6) entre los que tan sólo uno es un fragmento. En ellos se prioriza una de las caras como superficie de explotación, en la que se presentan diversos negativos de extracciones centrípetas de tamaño variable con el objetivo de preparar la superficie, mientras que las caras adyacentes funcionan a modo de plataforma de percusión. La longitud de estos núcleos se encuentra entre los 2,5 y $3,5 \mathrm{~cm}$, su anchura entre los 2,5 y $4 \mathrm{~cm}$, mientras que el espesor es bastante variable, desde 0,6 a $2,3 \mathrm{~cm}$, por lo tanto, de dimensiones similares a los núcleos discoides. De estos seis núcleos, 4 fueron realizados sobre nódulo frente a 2 sobre lasca; además la mitad presentan córtex, dos de ellos entre un 20 y 50\%. La curvatura de la superficie de explotación es plana (4) o convexa (2), mientras que su forma se reparte por igual entre una superficie rectangular estrecha (incluyendo los dos casos de curvatura convexa) y una superficie rectangular ancha. La longitud y anchura de las últimas extracciones oscila entre 1 y $2 \mathrm{~cm}$ aproximadamente. El carácter reducido de estas últimas extracciones sin duda se encuentra relacionado con el hecho de que cinco de estos núcleos se encuentren agotados y tan sólo uno en plena producción. Circunstancia que se explica por el aprovechamiento intenso de la materia prima.

En los soportes predominan los talones lisos (9), seguidos de los diedros (2) y de los facetados convexos (1); además hay 1 talón cortical y 5 piezas sin talón por fractura. Incluso en un sistema como el $\mathrm{Le}$ vallois de lascas recurrentes centrípetas, caracterizado por una planificación de la talla, llama la atención la escasa cantidad de talones que conllevan de forma clara una preparación de los puntos de impacto, si bien en proporción se supera a lo observado en los sistemas de talla analizados anteriormente. A excepción de dos soportes fruto del mantenimiento, los restos corresponden a la fase de plena explotación. Los dos soportes en fase de mantenimiento se corresponden con dos lascas desbordantes, piezas que evidencian el intento de recuperar la convexidad de las superficies de explotación de los núcleos durante el proceso de talla, para seguir obteniendo soportes predeterminados aplicando un criterio de recurrencia. Asimismo, escasean las superficies corticales y cuando se conservan son de poca extensión, tan sólo presentándose en 6 restos (en cinco de ellos por debajo del 20\%). Este sistema presenta 9 piezas incluidas en la Lista Tipo del Paleolítico medio (Bordes, 1988): 6 lascas Levallois atípicas, una raedera convergente, una desviada y una raedera sobre cara plana (Fig. 7).

En cuanto al sistema Levallois de lasca preferencial, está representado por 6 restos entre los que contamos con 3 núcleos (Fig. 6), todos completos. Estos se caracterizan por presentar un negativo de la extracción de una lasca preferencial que abarca casi toda la superficie de explotación, así como la preparación de las plataformas de percusión en los laterales del núcleo. Uno de los tres núcleos, perteneciente a MajonesLlacuna, presenta un tamaño destacable $(4,28 \mathrm{~cm}$ de longitud, 4,27 cm de anchura y 1,37 cm de espesor), mientras que los otros dos, procedentes de Pla de $\mathrm{Pa}$ lau, son más reducidos $(2,61 \mathrm{~cm}, 3 \mathrm{~cm}$ y $0,94 \mathrm{~cm} ; 2,79$ $\mathrm{cm}, 3 \mathrm{~cm}$ y 1,28 cm). Los tres se han realizado sobre nódulo y tan sólo el primero de Pla de Palau no presenta córtex. En los tres casos la superficie de explotación es plana y rectangular ancha. La longitud y anchura de las últimas extracciones se encuentra entre los 2 y 3 $\mathrm{cm}$, a excepción de la extracción del núcleo más grande, que alcanza los 3,47 $\mathrm{cm}$ de longitud. Los tres se presentan como agotados.

Entre las tres lascas Levallois preferenciales hay 1 talón liso (La Llacuna), 1 facetado convexo (Les 
Majones) y 1 suprimido (Pla de Palau). Todas corresponden a la fase de plena explotación y ninguna de ellas presenta córtex. Las tres se han empleado para realizar algún tipo de útil: la primera es una punta $L e$ vallois y las dos restantes son raederas simples convexas (Fig. 7).

\subsection{Otros SISTEMAS DE TALLA}

Se han identificado 6 piezas de morfología Kombewa $(1,41 \%)$ producidas a partir de lascas espesas. En este caso nos parece interesante destacar sus dimensiones: longitudes en torno a 1-2 cm, anchuras de entre 1,5 y $2,5 \mathrm{~cm}$ y espesores reducidos de entre 0,3 y $0,5 \mathrm{~cm}$. Así pues, se trata de soportes finos y de reducido tamaño. Entre los talones predominan los lisos (4), aunque también hay uno roto y una pieza sin talón por fractura. Todos se encuentran en la fase de plena explotación y son de tercer orden, a excepción, en cuanto a esto último, de uno de los fragmentos que presenta parte de córtex y por lo tanto es de segundo orden. La mitad de las piezas están retocadas y se trata en los tres casos de raederas: una raedera sobre cara plana (Pla de Palau), una doble recto-convexa y una desviada (ambas de Majones-Llacuna).

También conviene destacar el hallazgo de un bifaz en Pla de Palau (Fig. 8), confeccionado mediante la técnica del façonnage, consistente en dar forma relativamente apuntada a un bloque de materia prima a partir de la extracción de lascas de bifaz. Es de pequeño tamaño (4,06 cm de longitud, 2,86 cm de anchura y $1,49 \mathrm{~cm}$ de espesor) y está realizado sobre sílex de grano fino. El talón ha sido suprimido por la configuración del útil, pertenece a la fase de plena explotación y es de tercer orden. Presenta dos retoques: uno simple, continuo, bifacial y muy profundo; y otro simple, continuo, directo y profundo. La pieza destaca por ser un tipo de útil poco habitual en el Paleolítico valenciano (Villaverde, 1984; Fernández Peris, 2007).

Por último hay tres piezas que no pueden incluirse en ninguno de los sistemas anteriores. Se trata de un núcleo Quina, uno ortogonal y un chunk. El núcleo Quina se ha realizado sobre un nódulo y presenta unas dimensiones reducidas $(1,95 \mathrm{~cm}, 2,70 \mathrm{~cm}$ y 1,95 cm) (Fig. 6). Se caracteriza por la intersección de los planos de explotación, alternando las plataformas de percusión. Cuenta con unas superficies de explotación planas y de forma rectangular estrecha. Su última extracción mide 1,26 cm de longitud y 1,46 cm de anchura, y se encuentra agotado. El núcleo ortogonal está realizado sobre nódulo y mide $2,76 \mathrm{~cm}$ de longitud, 3,05 cm de anchura y 1,71 cm de espesor. Presenta más del 50\% de córtex y su superficie de explotación es convexa y de forma rectangular ancha. $\mathrm{Su}$ última extracción es de 1,09 $\mathrm{cm}$ de longitud por 1,97 cm de anchura y su estado es de plena producción. El chunk, sobre nódulo, es de morfología cúbica $(2,97$ $\mathrm{cm}, 3,11 \mathrm{~cm}$ y $3,11 \mathrm{~cm})$. La única superficie en la que hay un negativo de una extracción antrópica es plana y dicha extracción presenta una longitud de $2,8 \mathrm{~cm}$ por una anchura de $1,74 \mathrm{~cm}$. Se encuentra abandonado por defectos de la materia y puede que algunas de las extracciones que se aprecian sean de origen mecánico.

Finalmente conviene destacar la presencia de 121 restos $(28,47 \%)$ cuya técnica no se ha podido determinar, en muchos casos debido a que se trata de fragmentos de reducido tamaño o poca representatividad del total de la pieza original, o bien porque han sufrido alteraciones térmicas. Entre estos aparecen algunos útiles (Fig. 7), de los que podemos destacar 5 denticulados, un útil compuesto constituido como raedera doble recto-convexa y perforador, una raedera simple cóncava, un fragmento de hoja de laurel cuya fracturación se produjo durante el proceso de fabricación del útil, un fragmento de punta musteriense con reavivado intenso, un raspador ojival y una truncadura.

\subsection{FRAGMENTACIÓN DE LOS RESTOS}

Para cerrar este análisis tecnológico resulta interesante valorar la fragmentación del material, que nos puede aproximar a cuestiones de índole tafonómica, para lo cual se han calculado los índices de fragmentación, siguiendo los trabajos de Hiscock (2002), de cada uno de los cuatro conjuntos: Les Majones $(0,59)$, La Llacuna $(0,57)$ y Pla de Palau $(0,5)$ presentan un índice moderado, mientras que sólo Majones-Llacuna $(0,63)$ presenta un índice de fragmentación fuerte ${ }^{2}$ (Fig. 9). Aunque en tres de los casos los índices de fragmentación son moderados, dos de estos se encuentran muy próximos a ser considerados como fuertes, circunstancia coherente con el hecho de que se trate de un conjunto de superficie. El carácter no sistemático de las recogidas de material podría haber influido en que apareciera un mayor número de soportes completos al recoger los restos de mayor tamaño, no obstante, a juzgar por la cantidad de piezas laminares de pequeñas dimensiones y la destacada proporción de restos clasificados como debris, creemos que en muchos casos las recogidas pudieron ser bastante minuciosas. En cualquier caso el carácter superficial de los conjuntos obliga a tomar estos datos con cierta cautela.

\begin{tabular}{|c|c|c|c|c|}
\cline { 2 - 5 } \multicolumn{1}{c|}{} & $\begin{array}{c}\text { Les } \\
\text { Majones }\end{array}$ & La Llacuna & Pla de Palau & $\begin{array}{c}\text { Majones- } \\
\text { Llacuna }\end{array}$ \\
\hline Fragmentadas & 13 & 66 & 66 & 63 \\
\hline Total piezas & 22 & 115 & 131 & 100 \\
\hline If & 0,59 & 0,57 & 0,50 & 0,63 \\
\hline
\end{tabular}

Figura 9: Índices de Fragmentación (IF) de los materiales documentados en los yacimientos.

2. Debe tenerse en cuenta que en el cálculo de los índices no se han tenido en cuenta ni los núcleos ni el material clasificado como debris. 


\section{CONCLUSIONES}

El análisis de los cuatro conjuntos líticos aquí presentados evidencia la ocupación de esta zona durante el Paleolítico medio y superior. Este estudio se suma al anterior del yacimiento de Els Bancals de Pere Jordi (Eixea y Villaverde, 2012) en el esfuerzo de caracterizar la frecuentación de los territorios nororientales de la provincia de Alicante en el pasado, pero al contrario que en aquel caso, donde las piezas de las últimas fases del Paleolítico tenían poco peso, en este caso puede comprobarse la importancia de la ocupación de la zona en dichos momentos.

En base a la buena representación de núcleos y productos de talla, tanto del Paleolítico medio como del Paleolítico superior, resulta evidente que en estos lugares se desarrollaron procesos de talla guiados por distintos sistemas. En relación a esto conviene destacar dos piezas del Paleolítico medio procedentes de La Llacuna que muestran un cambio en las estrategias de talla, produciendo lascas discoides a partir de anteriores núcleos Levallois. Por otro lado, dada la abundancia de piezas retocadas de ambos periodos, parece que los grupos no sólo pudieron traerse los útiles consigo, sino que también los confeccionarían en el lugar, como se desprende por ejemplo de la fractura producida durante la configuración de una hoja de laurel de Les Majones. En cualquier caso, la presencia de estos útiles denota su uso en estos sitios y su posterior abandono. Al tratarse de materiales de superficie y cuya recogida no ha sido de carácter sistemático, prácticamente no aparecen pequeñas esquirlas de talla o configuración y reavivado de los filos, ya que la mayor parte de los restos definidos como debris creemos que es resultado de la fracturación de piezas más grandes en fragmentos de dimensiones reducidas por la acción del fuego, del trampling de personas y animales u otros procesos. Además se constata el reciclaje de ciertos restos, especialmente de tres productos de acondicionamiento de núcleo aprovechados para realizar dos piezas astilladas y un raspador; así como una antigua lasca en cuya superficie se formó neocórtex y que se habría recogido para fabricar un perforador en el Paleolítico medio, pieza que muestra cómo estos yacimientos al aire libre también pudieron servir como fuente de materia prima para ocupantes posteriores.

En cuanto al estudio tecnológico de los materiales del Paleolítico superior, se trata de una industria caracterizada por soportes alargados y finos, como muestran las numerosas láminas (72) y laminitas (27) recuperadas, así como los núcleos laminares (31), explotados tanto de forma unipolar como bipolar. No obstante, también conviene destacar la existencia de una talla de lascas, más difícil de asociar a este periodo al tratarse de conjuntos con abundantes restos del $\mathrm{Pa}$ leolítico medio, aunque identificable a partir de diversos útiles propios del Paleolítico superior fabricados sobre lasca, especialmente raspadores y piezas astilladas. Conviene destacar que en muchos de los núcleos la última extracción no es de carácter microlaminar
(18) y la mayoría se encuentran en un estado de plena producción (21), hechos que pueden evidenciar un aprovechamiento no demasiado exhaustivo de la materia prima. Esto, junto con el pequeño tamaño de los soportes microlaminares que los hace más difíciles de identificar en yacimientos en superficie, puede explicar el reducido número de laminitas en comparación con el de láminas, piezas que sin embargo son abundantes en los conjuntos del Paleolítico superior de la Fachada Mediterránea Peninsular (Cacho et alii, 2001; Langlais, 2007; Zilhão et alii, 2010; Villaverde et alii, $2012 b)$. Del proceso de producción de soportes destaca la buena representación de los PAN (17) y la escasa preparación de los puntos de percusión a juzgar por la escasez de talones lineales (3) o diedros (2). Entre el material retocado destaca la abundancia de raspadores y la presencia reducida de buriles y utillaje de dorso.

La documentación de foliáceos, como son las hojas de laurel de Les Majones y Pla de Palau, así como de puntas de cara plana en Pla de Palau (Fig. 8), apunta a la ocupación de estos lugares durante el Solutrense medio o superior, inclinándonos más hacia el Solutrense superior en base a la morfología marcadamente alargada de la hoja de laurel de Pla de Palau. Conviene destacar que el fragmento de foliáceo hallado en La Llacuna genera más dudas, ya que podría ser atribuido tanto al Solutrense, si se tratase de una hoja de laurel, como a etapas postpaleolíticas como el Calcolítico (J. Juan Cabanilles com. pers.), en este último caso en función de su tamaño y morfología general. También es necesario matizar que las piezas definidas como puntas de cara plana son en ambos casos dos fragmentos laminares en los que no está representada la parte proximal, por lo que no se puede afirmar con rotundidad que se trate de este tipo aunque es el más probable. De todos modos, la presencia durante este periodo queda constatada en las áreas más inmediatas del lugar en los yacimientos de La Safor como son Parpalló (Gandía) y Malladetes (Barx), a los que junto a estos nuevos hallazgos se sumarían otros conjuntos como Meravelles (Gandía), Barranc Blanc (Ròtova), los del núcleo de la Marina Alta y, más al sur, Tossal de la Roca (la Vall d'Alcalà), Cova Fosca (la Vall d'Ebo) o la Cova del Randero (Pedreguer).

También podría estar representado el Solútreo-gravetiense, dada la presencia de un fragmento distal de punta de dorso en La Llacuna que podría corresponder a una punta escotada. No obstante, esta misma pieza podría evidenciar ocupaciones del Gravetiense en caso de tratarse de un fragmento de punta de La Gravette; a esto se suman dos fragmentos de hojitas de dorso apuntadas (ambas de Pla de Palau) que podrían corresponder a microgravettes. Del mismo modo se podría defender la presencia de elementos del Magdaleniense en base a este microutillaje de dorso, así como a partir de los diversos núcleos con extracciones microlaminares ( 2 en Les Majones y La Llacuna, 5 en Pla de Palau y 4 en Majones-Llacuna). En cualquier caso las evidencias que pueden adscribirse a estos periodos no son claras, ya 
que en el caso del Gravetiense o el Solútreo-gravetiense no se cuenta con piezas de dorso completas, mientras que en lo referente al Magdaleniense faltan tipos microlaminares característicos como las hojitas de finos retoques o de retoque inverso, además de la escasa presencia de buriles (1 en La Llacuna y 2 en Pla de Palau y Majones-Llacuna). Estos problemas de identificación se producen por la destacada fragmentación del material en estos conjuntos de superficie, en lo que respecta a las piezas de dorso, y pueden deberse a la propia recogida no sistemática en cuanto a la ausencia de microutillaje típico del Magdaleniense. Por otro lado, a diferencia de Els Bancals de Pere Jordi (Eixea y Villaverde, 2012), dónde en los materiales estudiados se han encontrado algunos elementos típicos del Auriñaciense, en este caso no se han documentado piezas que se puedan atribuir a las fases más antiguas del Paleolítico superior. Por lo tanto, los únicos momentos en los que se tiene constancia clara de presencia humana en estos lugares es durante el Solutrense medio o superior, aunque se cuenta con evidencias de su frecuentación en otros momentos del Paleolítico superior difíciles de precisar.

En relación a las piezas del Paleolítico medio, es una industria caracterizada por la producción de lascas de morfología cuadrangular y relativamente espesas. Esto se debe sobre todo al desarrollo del sistema de talla discoide (27\%), aunque también hay evidencias del método Levallois (7\%) en sus dos técnicas, preferencial y recurrente centrípeta; por otro lado, no se han identificado restos Levallois laminares, como evidenciaría la presencia de esquemas recurrentes unipolares y bipolares. La mayoría de núcleos discoides se encuentra en un estado de plena producción, mientras que los Levallois están casi todos agotados, en ambos casos con últimas extracciones de dimensiones muy reducidas (la mayoría en torno a 1-2 cm de longitud y anchura), hecho que evidencia la producción de soportes de tamaño muy reducido en concordancia con lo visto en otros conjuntos del Paleolítico medio a nivel regional (Villaverde et alii, 2012a). Por otro lado, como ya se ha visto para las piezas del Paleolítico superior, en el caso del Paleolítico medio también hay una escasa preparación de los puntos de percusión. Los soportes Levallois son en mayor medida destinados a la fabricación de útiles. Entre los soportes retocados predominan las raederas, las más numerosas las simples convexas, pero también destaca la elevada representación de muescas y denticulados así como de los cuchillos de dorso; además cabe señalar el hallazgo de un bifaz, que en la línea de lo visto en el resto de conjuntos valencianos de este periodo, su presencia no deja de ser testimonial.

Al igual que hemos visto para el Paleolítico superior, durante el Paleolítico medio esta zona es una de las más ricas del territorio valenciano con unos conjuntos que abarcan todo el lapso temporal que discurre desde el MIS 7 al 5, atestiguado en la Cova del Bolomor (Tavernes de la Valldigna), Cova del Corb (Ondara) y en parte de la secuencia de Cova Negra (Xàtiva). En momentos más recientes, durante el MIS 5 al 3, el número de yacimientos se amplía con la presencia de la Cova de la Petxina (Bellús), Cova Foradada (Oliva) y Cova del Puntal del Gat (Benirredrà), más al sur en El Salt (Alcoi), Beneito (Muro d'Alcoi), y en los yacimientos de superficie de Penella y Coves d'Estroig (Cocentaina) y l'Alt de la Capella (Benifallim).

La valoración de estos conjuntos resulta de gran interés a nivel diacrónico, dada la presencia de restos líticos de distintos periodos. Así pues, la frecuentación de la zona durante el Paleolítico medio está ampliamente demostrada, gracias a la gran cantidad de restos líticos atribuibles a este periodo que componen tanto los conjuntos presentados en este trabajo como el de Els Bancals de Pere Jordi (Eixea y Villaverde, 2012); incluso se puede apuntar a ocupaciones más antiguas a partir de la identificación del bifaz de Pla de Palau, aunque como es sabido, tanto la baja densidad de este tipo de útil en territorio valenciano como la morfología que presenta, hace muy complicado adscribirlo cronológicamente.

Además en esta ocasión se ha podido constatar con un mayor número de efectivos la ocupación de la zona durante el Paleolítico superior, especialmente durante el Solutrense. También es posible que se acudiera a estos lugares en épocas posteriores de la Prehistoria, en caso de que el foliáceo más arriba referido sea Calcolítico. Por último conviene destacar la presencia de restos líticos de época histórica, no incluidos por ello en el estudio tecnológico. Se trata concretamente de cuatro piedras de fusil, empleadas para prender la mecha de armas de fuego a partir de la Edad Moderna y cuyo uso se multiplica a principios del s. XVIII al convertirse este tipo de armas en las reglamentarias de los ejércitos reales (Roncal et alii, 1996).

La ubicación de estos conjuntos de superficie denota la importancia de esta área, al emplazarse entre dos importantes corredores que conectan las llanuras litorales al noreste con el interior montañoso al suroeste: los valles del río Serpis y el Gallinera. A este respecto cabe destacar que los tres conjuntos de los que se conoce el emplazamiento se encuentran en las zonas bajas del área estudiada: Les Majones se sitúa al pie de la Serra de la Safor, La Llacuna en la llanura existente entre la Serra de la Safor y la Serra de l'Almirant y Pla de Palau en las zonas más bajas de la vertiente meridional de la Serra de l'Almirant. Además dos de ellos, Les Majones y Pla de Palau, cuentan con un curso fluvial, río Serpis y Gallinera respectivamente, a no más de $1 \mathrm{~km}$ de distancia. De este modo se aprecia que los asentamientos se encuentran en corredores naturales que conectan áreas con importante ocupación paleolítica, como el núcleo de yacimientos de la Safor al norte y el de el Comtat - l'Alcoià al suroeste, y algunos de ellos próximos a fuentes de agua. Así pues, no se trata de asentamientos que se caractericen por contar con un buen control del territorio desde zonas altas, sino que más bien se emplazan en zonas de paso y su condición de yacimientos al aire libre los haría habitables sólo en determinados periodos del año o bien durante periodos cortos en épocas menos favorables, empleándolos como 
campamentos temporales ocupados en los movimientos interior-costa. Al tratarse de conjuntos de materiales sin contexto estratigráfico, recogidos de forma no sistemática y sin un registro de la localización de los hallazgos, no nos es posible realizar más comentarios en relación a las características y la función de estos asentamientos.

En cualquier caso, el número de yacimientos al aire libre en esta área pone de relieve la importancia de este tipo de asentamientos durante el Paleolítico, importancia que se ha visto siempre minimizada por el mayor número de yacimientos conocidos en cuevas o abrigos, debido en gran parte a una investigación generalmente más centrada en estos contextos, y el mejor estado de conservación que suelen presentar estos. La baja visibilidad arqueológica de los yacimientos al aire libre es uno de los problemas que condicionan su subrepresentación y provocan un sesgo en la investigación. En el ámbito peninsular cabe destacar algunos que conservan estratigrafía, estudiados a lo largo de varios años y con niveles de cronologías muy dispares: Torralba y Ambrona, con ocupaciones del Paleolítico inferior, situados en el área donde se encuentra el Sistema Central con la Cordillera Ibérica al SE de la provincia de Soria; los diversos yacimientos del Paleolítico inferior y medio del río Palmones (Cádiz); el taller gravetiense de Mugarduia sur en la Sierra de Urbasa (Navarra); el conjunto de yacimientos con cronologías que van del Gravetiense al Magdaleniense en el Valle del Cõa (NE de Portugal); las ocupaciones solutrenses de Las Delicias (Madrid), del río Palmones (Cádiz) y del Pantano de Cubillas (Granada), todas vinculadas a cursos fluviales; los yacimientos magdalenienses de Montlleó en el Pirineo catalán (Lleida), La Dehesa (Salamanca) y Foz do Medal junto al río Sabor (NE de Portugal); o el yacimiento epipaleolítico de Berniollo, en la cuenca del río Bayas (Álava).

No obstante, los problemas de conservación que caracterizan a este tipo de asentamientos (erosión natural del suelo por diversos agentes climáticos al quedar expuestos a la intemperie, alteración por trabajos agrícolas, etc.) conllevan que en la mayoría de casos sólo se tenga constancia de restos arqueológicos superficiales carentes de contexto estratigráfico. Muchos de los yacimientos de superficie que se han estudiado se encuentran en el interior peninsular y presentan ocupaciones del $\mathrm{Pa}-$ leolítico inferior o medio: el yacimiento musteriense de Castelló del Pla (Huesca), el achelense-musteriense de El Palacio (Valladolid), los achelenses de El Basalito y Los Tablazos (Salamanca), los hallazgos musterienses del abanico aluvial del Guadiana Alto (Ciudad Real) y los de la cuenca del río Mundo o el yacimiento de Los Almendros (Albacete) adscritos también al Musteriense. En la zona meridional destaca el completo estudio de los conjuntos del Paleolítico inferior y medio del río Corbones (Sevilla), así como los hallazgos del Paleolítico medio de Las Toscas y Loma Fonseca (Murcia). Finalmente cabe señalar algunos yacimientos de zonas más próximas a la costa y pertenecientes al Paleolítico superior, como son Cubeta de la Paja (Cádiz), adscrito al Solutrense evolucionado, el yacimiento magdaleniense de Leginpea (Navarra) o el epimagdaleniense de Sant Joan de Nepomucé (Castellón).

De este modo se aprecia el buen número de yacimientos del Paleolítico inferior y medio presentes en la Meseta y el sur de la Península, aunque su carácter superficial condiciona en gran medida las conclusiones que se pueden extraer de su estudio. La ausencia de restos del Paleolítico superior en muchos de ellos facilita que algunos gocen de mayor coherencia cronológica, característica con la que no cuentan los conjuntos aquí estudiados al encontrarse en lugares ocupados de forma reiterada por distintos grupos culturales a lo largo de un dilatado periodo de tiempo. Por el contrario, si bien la representación de ocupaciones del Paleolítico superior en el interior peninsular parece un poco menor, en muchos de ellos se han realizado excavaciones, recuperando principalmente evidencias del Solutrense y el Magdaleniense, lo que permite conocer mejor las características de los modos de ocupación al aire libre durante estos periodos. Su menor proporción, en comparación con la de yacimientos de periodos antiguos, sólo puede explicarse por problemas de conservación o de visibilidad. En cuanto a las zonas peninsulares más próximas a la costa, se aprecia que a pesar de que cuentan con una tradición investigadora cuya atención ha basculado hacia los depósitos en cuevas y abrigos, también se conoce un buen número de ocupaciones al aire libre de distintos periodos en estos ámbitos. Por último, conviene destacar que muchos de estos yacimientos, ya sean de etapas más antiguas o más recientes del Paleolítico, se emplazan en zonas bajas y vinculados a cursos fluviales, aspecto en el que coinciden con algunos de los conjuntos analizados en este trabajo.

Estas circunstancias dotan de gran importancia a yacimientos como los aquí presentados, al permitir estudiar el poblamiento en espacios al aire libre a lo largo del Paleolítico, aunque teniendo siempre presente las grandes limitaciones con que cuentan los conjuntos de superficie a la hora de analizarlos e interpretarlos. El buen emplazamiento en el que se encuentran los materiales aquí presentados y los procedentes de Els Bancals de Pere Jordi, explica la reiterada frecuentación de estos puntos en distintos momentos del Paleolítico, tanto si se ocupaban durante periodos cortos de unos pocos días como de forma estacional a lo largo de varias semanas o meses. Por lo tanto, esta zona se postula como un ámbito geográfico con gran potencial arqueológico, sobre el que será conveniente ampliar los estudios en un futuro. Probablemente, el vínculo a zonas de paso abre una nueva perspectiva al estudio del poblamiento en la zona y puede ser una de las claves en la interpretación de yacimientos de estas características.

\section{Agradecimientos}

Agradecemos a Manuel Sánchez las facilidades prestadas para el estudio del material, así como al profesor Valentín Villaverde por las correcciones, matizaciones 
y opiniones que nos ha prestado. Además queremos agradecer a los revisores anónimos sus comentarios y la información de carácter geográfico aportada. Los materiales objeto de estudio en este trabajo han sido depositados en los fondos del Museu de Prehistòria de València. La investigación de este trabajo se ha beneficiado de las siguientes ayudas: «El final del Paleolítico medio y el Paleolítico superior en la región central del Mediterráneo ibérico» (FFI 2008-01200/FISO) y «Paleolítico medio final y Paleolítico superior inicial en la región central mediterránea (Valencia y Murcia)» (HAR2011-24878).

Miguel Ángel Bel Martínez
Aleix Eixea Vilanova
Departament de Prehistòria i Arqueologia
Universitat de València.
Avda. Blasco Ibáñez, 28
46010 València
miguel.bel@uv.es
alejo.eixea@uv.es

\section{BIBLIOGRAFÍA}

BEAVITT, P., CHRISTIE, N. y GISBERT, J.A., 1995: «Serra de l'Almirant Survey Project: 1994 report», Saguntum, 28, 229-244.

BOËDA, E., 1993: «Le débitage discoïde et le débitage Levallois récurrent centripète», Bulletin de la Société Préhistorique Française, 90, 392-404.

BOËDA, E., 1994: Le concept Levallois:variabilité des méthodes, Monographie, 9, Paris.

BOËDA, E., GENESTE, J.-M. y MEIGNEN, L., 1990: «Identification de chaînes opératoires lithiques du Paléolithique ancien et moyen», Paléo, 2, 43-80.

BORDES, F., 1988: Typologie du Paléolithique Ancien et Moyen, Publications de l'Institut de Préhistoire de l'Université de Bordeaux, Mémoire 1, Bordeaux.

CACHO, C., JORDÀ, J., DE LA TORRE, I. y YRAVEDRA, J., 2001: «El Tossal de la Roca (Alicante). Nuevos datos sobre el Magdaleniense mediterráneo de la Península Ibérica», Trabajos de Prehistoria, 58, 71-95.

EIXEA, A. y VILLAVERDE, V., 2012: «Materiales líticos del Paleolítico medio y superior del yacimiento de superficie de Els Bancals de Pere Jordi (la Vall de Gallinera, Alicante)», Archivo de Prehistoria Levantina, XXIX, 65-79.

EIXEA, A., VILLAVERDE, V. y ZILHÃO, J., 2011: «Aproximación al aprovisionamiento de materias primas líticas en el yacimiento del Paleolítico medio del Abrigo de la Quebrada (Chelva, Valencia)», Trabajos de Prehistoria, 68 (1), 65-78.

FERNÁNDEZ PERIS, J., 2007: La Cova del Bolomor (Tavernes de la Valldigna, Valencia), Trabajos Varios del SIP 108, Valencia.

GALVÁN, B., HERNÁNDEZ, C. M., ORTEGA, F., MOLINA, F. J. y TARRIÑO, A., 2009: «La producción lítica del Abric del Pastor (Alcoi, Alicante). Un ejemplo de variabilidad musteriense», Tabona, 17, 11-61.
HISCOCK, P., 2002: "Quantifying the Size of Artefact Assemblages», Journal of Archaeological Science, 29, 251-258.

ITURBE, G., FUMANAL, M.P., CARRIÓN, J., CORTELL, E., MARTÍNEZ, R., GUILLEM, P., GARRALDA, M.D. y VANDERMEERSCH, B., 1993: «Cova Beneito (Muro, Alicante): una perspectiva interdisciplinar», Recerques del Museu d'Alcoi, 2, 23-88.

LANGLAIS, M., 2007: Dynamiques culturelles des sociétés magdaléniennes dans leurs cadres environnementaux. Enquête sur 7000 ans d'évolution de leurs industries lithiques entre Rhône et Èbre, Tesis doctoral. Inédita. Université de Toulouse.

MOLINA HERNÁNDEZ, F.J., TARRIÑO VINAGRE, A., GALVÁN SANTOS, B. y HERNÁNDEZ GÓMEZ, C.M., 2010: «Áreas de aprovisionamiento de sílex en el Paleolítico Medio en torno al Abric del Pastor (Alcoi, Alicante). Estudio macroscópico de la producción lítica de la colección Brotons», Recerques del Museu d'Alcoi, $19,65-80$

MOURRE, V., 2003: «Discoïde ou pas discoïde? Réflexions sur la pertinence des critères techniques définissant le débitage discoïde», en M. Peresani (ed.), Discoid Lithic Technology, Advances and Implications, BAR International Series, 1120, 1-18, Oxford.

ROMÁN, D., 2004: «Aproximación a la tecnología lítica del Magdaleniense superior de la Cova de les Cendres (Teulada-Moraira, Alacant)», Saguntum, 36, 9-23.

RONCAL, M.E., MARTÍNEZ, G. y MORGADO, A., 1996: «Las piedras de chispa: una producción lítica olvidada en España», Munibe, 48, 105-123.

SLIMAK, L., 2003: «Les débitages discoïdes moustériens: évaluation d'un concept technologique», en M. Peresani (ed.), Discoid Lithic Technology, Advances and Implications, BAR International series, 1120, 33-62, Oxford.

VILLAVERDE, V., 1984: La Cova Negra de Xàtiva y el musteriense de la región central del mediterráneo español, Trabajos Varios del SIP 79, Valencia.

VILLAVERDE, V., EIXEA, A., RIOS, J. y ZILHÃO, J., 2012a: «Importancia y valoración de la producción microlevallois en los niveles II y III del Abrigo de la Quebrada (Chelva, Valencia)», Zephyrus, LXX, 13-32.

VILLAVERDE, V., ROMÁN, D., PÉREZ RIPOLL, M., BERGADÀ, M. y REAL, C., 2012b: «The end of the Upper Palaeolithic in the Mediterranean Basin of the Iberian Peninsula», Quaternary International, 272-273, 17-32.

ZILHÃO, J., ANGELUCCI, D., BADAL, E., LUCENA, A., MARTÍN, I., MARTÍNEZ, S., VILLAVERDE, V. y ZAPATA, J., 2010: «Dos abrigos del Paleolítico superior en Rambla Perea (Mula, Murcia)», en X. Mangado (ed.), Jornadas Internacionales sobre el Paleolítico superior peninsular. Novedades del Siglo XXI, Monografies del SERP, 8, 137-148, Barcelona.

Recepción: 28-01-2015

Aceptación: 06-05-2015 